\title{
Atitudes e motivações em relação ao consumo de alimentos orgânicos em Belo Horizonte - MG
}

\section{Attitudes and motivations towards organic foods consumption in Belo Horizonte, MG}

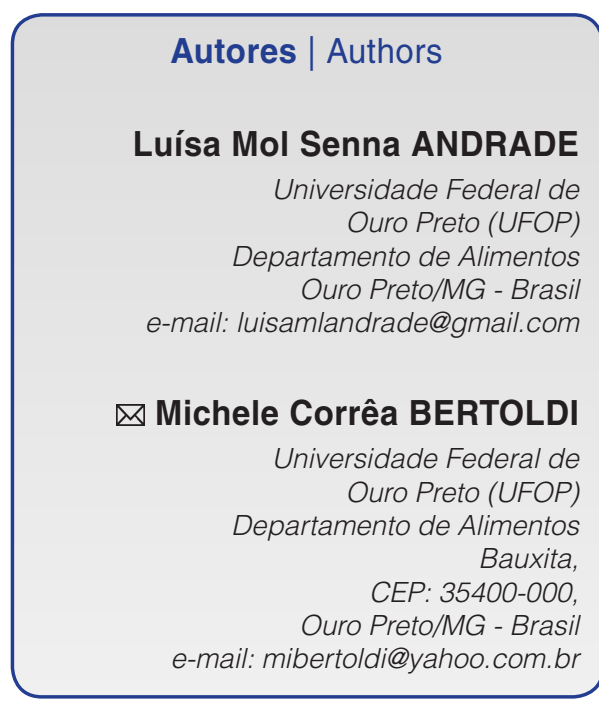

\ Autor Correspondente / Corresponding Author Publicado / Published: dezembro/2012

\section{Resumo}

O objetivo deste estudo foi caracterizar o mercado consumidor de alimentos orgânicos em Belo Horizonte-MG, incluindo o perfil socioeconômico e o comportamento dos consumidores, sua percepção e seu conhecimento sobre alimentos orgânicos, além das principais motivações e limitações em relação ao consumo desses produtos. Uma pesquisa descritiva direta e estruturada (survey) foi realizada com 400 consumidores de alimentos orgânicos, por meio da aplicação de questionários semiestruturados. A maioria dos consumidores era do gênero feminino (76,0\%), com idade superior a 30 anos (90,3\%), em união estável $(81,3 \%)$, graduados $(81,5 \%)$ e com renda familiar elevada (acima de 12 S.M./mês) $(78,7 \%)$. A maioria definiu alimento orgânico como um alimento isento de resíduos de agrotóxicos (69,7\%). Alimentos orgânicos foram mencionados conter maiores níveis de nutrientes do que os convencionais (82,0\%), além de serem isentos de organismos geneticamente modificados $(75,0 \%)$ e produtos químicos sintéticos $(86,0 \%)$. A maioria mostrou preocupação em manter hábitos de vida saudáveis, sendo que $80,5 \%$ exercitavam-se regularmente e $49,2 \%$ já haviam feito alguma dieta ou recebido orientações nutricionais. Todos acreditavam nos benefícios à saúde advindos do consumo dos produtos orgânicos e quase a totalidade $(98,8 \%)$ já havia percebido melhorias na saúde em decorrência desse consumo. Somente $16,3 \%$ consumiam outros alimentos orgânicos além de frutas e hortaliças. A preocupação com a saúde, assim como o maior conteúdo de nutrientes e o sabor mais pronunciado do que os alimentos convencionais, foram as maiores motivações para o consumo de frutas e hortaliças orgânicas. Grande parte dos consumidores apresentou conhecimento superficial sobre a temática, o que evidenciou a necessidade de maiores esclarecimentos sobre o assunto. Uma demanda reprimida por tais produtos pôde ser observada, pois, apesar do grande interesse por alimentos orgânicos, fatores como preço elevado e baixa qualidade limitaram o consumo destes produtos em Belo Horizonte.

Palavras-chave: Alimento orgânico; Comportamento; Frutas; Hortaliças; Percepção. 


\section{Summary}

The aim of this study was to characterize the consumer market of organic foods in Belo Horizonte, M.G., including the socioeconomic profile and consumer's behavior, their perception and knowledge regarding organic food, and also the main motivations and limitations towards the consumption of these products. A direct descriptive and structured research (survey) was carried out with 400 consumers, by using semi-structured questionnaires. Most consumers were female (76.0\%), aged over 30 years $(90.3 \%)$, in a stable relationship (81.3\%), degree holders (81.5\%), with high household income (over 12 M.S./month) (78.7\%). The majority defined organic food as foods without pesticide residues (69.7\%). Organic foods were mentioned to contain higher levels of nutrients than conventional foods (82.0\%), no genetically modified organisms $(75.0 \%)$ and no synthetic chemical products (86.0\%). The majority was worried about healthy life habits, since $80.5 \%$ regularly exercised and $49.2 \%$ had already gone on a diet or followed nutritional orientation. All believed in health benefits from consumption of these foods and almost all (98.8\%) had already noticed health improvements derived from consumption. Only $16.3 \%$ consumed organic food other than fruits and vegetables. Heath concern as well as the higher content of nutrients and more pronounced taste than conventional food were the major motivations for consumption of organic fruit and vegetables. A great part of consumers showed superficial knowledge regarding the issue, evidencing the need for better elucidation about the subject. A repressed demand for these products was observed, since, despite of high interest in organic foods, the high price and low quality limited the consumption of these products in Belo Horizonte.

Key words: Organic food; Behavior; Fruit; Vegetables; Perception. 


\section{Introdução}

O crescente interesse pelo consumo de alimentos com maior valor nutritivo e menor teor de contaminantes, além da busca por hábitos de vida mais saudáveis, têm contribuído para impulsionar o consumo de alimentos orgânicos, cujo mercado cresceu em torno de $20 \%$ ao ano, nos últimos anos (HOEFKENS et al., 2009; SCIALABBA, 2005; FAO, 2011).

A expressiva expansão do consumo de alimentos orgânicos no Brasil tem estimulado a demanda por estudos sobre o comportamento dos consumidores, visando à sua compreensão, de forma a direcionar o processo de comercialização e aumentar o consumo (PIMENTA, 2008). Informações sobre o comportamento dos consumidores e dos principais fatores que influenciam a sua decisão de compra são essenciais para identificação de oportunidades de mercado (SILVA, 2003).

O conhecimento do perfil dos consumidores de alimentos orgânicos e dos fatores que motivam ou limitam o seu consumo mostra-se vital para promover a expansão do mercado, de modo a adequá-lo às expectativas e necessidades dos consumidores em termos de produtos e serviços. Por outro lado, tais informações contribuem para definir estratégias e demandas de mercado, além de direcionar o processo de propaganda e comunicação, o qual poderia, por exemplo, disseminar informações mais relevantes para os potenciais consumidores, como a disponibilidade dos produtos e os benefícios da oferta, bem como as maneiras e os locais onde obter os produtos (VILAS BOAS et al., 2006). Informações sobre o perfil dos consumidores e previsões de mercado também favorecem o direcionamento de políticas públicas governamentais, de modo a promover o crescimento do setor de orgânicos e, por conseguinte, estimular a expansão da agricultura familiar no País.

Nesse contexto, o objetivo deste estudo foi caracterizar o mercado consumidor de alimentos orgânicos na cidade de Belo Horizonte-MG, bem como seus hábitos e principais motivações e limitações em relação ao consumo desses alimentos.

\section{Material e métodos}

Para o levantamento dos dados, foi realizada uma pesquisa descritiva direta e estruturada (survey) na capital do Estado de Minas Gerais, Belo Horizonte (19.597.330 habitantes, IBGE, 2011), no período de julho a dezembro de 2011, em supermercados e feiras, nos quais os alimentos orgânicos são comercializados. As entrevistas foram realizadas mediante aplicação de questionários semiestruturados a consumidores de frutas e hortaliças orgânicas, selecionados de forma aleatória. A abordagem do questionário incluiu questões sobre o perfil socioeconômico dos consumidores de frutas e hortaliças orgânicas, os hábitos, o grau de interesse em consumir alimentos orgânicos ( 1 = nenhum a 5 = grande $)$, a percepção e o conhecimento sobre a temática, as preferências, os meios de comunicação utilizados e a satisfação em relação aos produtos ofertados, além das principais motivações e limitações do consumo. $\mathrm{O}$ tamanho da amostra $(n=400)$ foi definido considerando-se um nível de confiança de 95\%, margem de erro de 4,9\% e variabilidade máxima de $50 \%$, conforme descrito em Endo et al. (2009). As entrevistas foram realizadas segundo as orientações do Comitê de Ética em Pesquisa (SISNEP/CAAE 2011 0069.0.238.000-10). Os dados foram categorizados e analisados, de forma descritiva, utilizando-se o programa estatístico licenciado IBM SPSS versão 19.0 .

\section{Resultados e discussão}

A maioria dos consumidores de alimentos orgânicos era do gênero feminino $(76,0 \%)$, com idade mínima de 31 anos (90,3\%). Dos entrevistados, a maioria mantinha união estável $(81,3 \%)$ e tinha entre um e quatro filhos $(82,7 \%)$, dos quais pelo menos um tinha idade até 18 anos (78,7\%). O nível de escolaridade predominante entre os entrevistados foi o Ensino Superior $(81,5 \%)$, enquanto a renda familiar mensal foi de 12 salários mínimos (6.541 reais) ou mais (78,7\%). Em Belo Horizonte - MG, o perfil sóciodemográfico dos consumidores de frutas e hortaliças orgânicas (Figura 1) foi similar àqueles encontrados em estudos similares, realizados com consumidores de alimentos orgânicos (MAGNUSSON et al., 2003; MEI-FANG, 2007; NESS et al., 2010), em que as mulheres normalmente predominam entre os consumidores, bem como os indivíduos com renda e nível de escolaridade elevados.

Em se tratando do conceito de "alimento orgânico", a maioria dos consumidores o definiu como um alimento isento de agrotóxicos ou pesticidas $(69,7 \%)$, ou de produtos químicos (14,5\%) (Figura 2).

A maioria $(75,0 \%)$ dos entrevistados afirmou que organismos geneticamente modificados (OGM) não são utilizados em alimentos orgânicos, enquanto outros afirmaram que são utilizados em quantidade inferior $(13,3 \%)$ à dos alimentos convencionais; uma parcela significativa (10\%), entretanto, afirmou desconhecer estas informações. A maioria também mencionou que produtos químicos sintéticos não são utilizados (86\%), embora outros tenham afirmado que estes são encontrados em menor quantidade (13\%). Segundo a legislação brasileira, a eliminação do uso de OGM é a base do conceito de sistema orgânico de produção agropecuária, assim como a contraposição ao uso de materiais sintéticos, usados apenas em casos excepcionais (BRASIL, 2003, 2011). Portanto, estes resultados refletem o desconhecimento de uma parcela considerável da população em relação ao assunto. 
Atitudes e motivações em relação ao consumo de alimentos orgânicos em Belo Horizonte - MG

ANDRADE, L. M. S. e BERTOLDI, M. C.

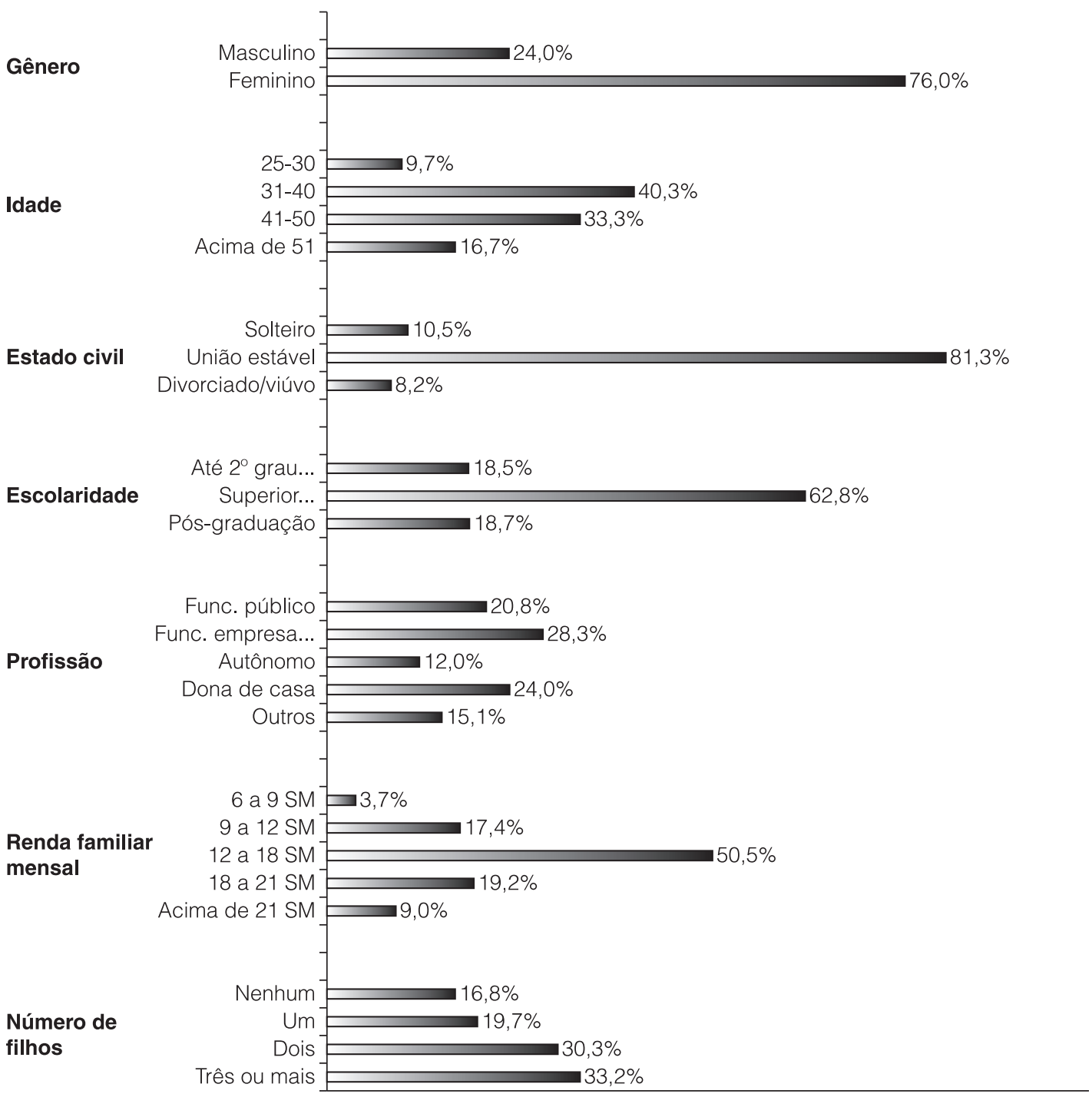

Figura 1. Perfil sociodemográfico dos consumidores de frutas e hortaliças orgânicas em Belo Horizonte, Minas Gerais.

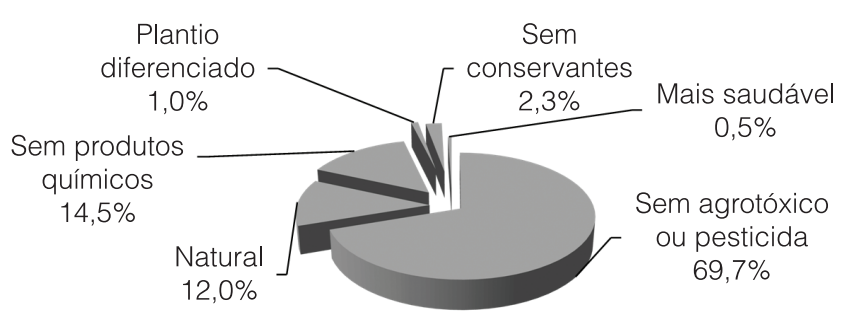

Figura 2. Frequência relativa do conceito de alimento orgânico, segundo os entrevistados.

A maioria acreditava que o cultivo orgânico não polui $(38,8 \%)$ ou polui menos $(47,5 \%)$ o meio ambiente, enquanto os demais afirmaram que este sistema polui mais $(0,8 \%)$ ou na mesma intensidade $(13,0 \%)$ que o sistema convencional. Além disso, grande parte dos entrevistados indicou os pequenos produtores ou os agricultores familiares como os mais beneficiados pela produção orgânica (51,8\%), enquanto grandes produtores
$(16,5 \%)$ ou ambos $(30,5 \%)$ foram mencionados pelo restante.

Em se tratando da percepção dos consumidores quanto ao nível de nutrientes, a maioria (82,0\%) afirmou que este é maior em alimentos orgânicos do que nos convencionais. Ademais, todos os entrevistados afirmaram acreditar nos benefícios à saúde advindos do consumo de alimentos orgânicos e quase a totalidade (98,8\%) já percebeu melhorias na saúde em decorrência do consumo destes alimentos. Vários estudos relatam que, em geral, os consumidores de alimentos orgânicos valorizam o prazer do bem-estar e da vida saudável (VILAS BOAS et al., 2006). Assim, sua preferência é determinada, entre outras razões, por uma percepção de que estes alimentos podem trazer mais benefícios à saúde do que os convencionais (ANKOMAH e YIRIDOE, 2006), além de apresentarem melhor qualidade e maior segurança alimentar (MEI-FANG, 2007). Outros resultados desse estudo também elucidam a busca destes 
consumidores por hábitos de vida mais saudáveis, uma vez que a maioria (80,5\%) dos entrevistados se exercitava regularmente (frequência semanal) (Figura 3), enquanto grande parte $(49,2 \%)$ afirmou fazer ou já ter feito algum tipo de dieta, ou receber ou ter recebido orientações nutricionais.

A maioria dos consumidores (98,8\%) afirmou que não houve um evento decisivo que os tenha levado a iniciar o consumo de alimentos orgânicos. Além disso, apenas $8,3 \%$ afirmaram ter algum tipo de restrição alimentar (açúcar, gordura ou carne vermelha). Estes resultados sugerem que, na maioria das vezes, o consumo de alimentos orgânicos não é iniciado em razão de uma necessidade. Em geral, o consumo destes alimentos é motivado, principalmente, pela busca de um estilo de vida mais saudável, que inclui uma alimentação balanceada e com conteúdo reduzido de substâncias tóxicas (ILYASOGLU et al., 2010; GUIVANT, 2003; MAGNUSSON et al., 2003; ROITNERSCHOBESBERGER et al., 2008; WILLIAMS e HAMMITT, 2001).

Embora a maioria dos entrevistados tenha manifestado interesse de moderado $(73,3 \%)$ a grande $(15,0 \%)$ no consumo de alimentos orgânicos, a comercialização destes alimentos em Belo Horizonte abrangeu basicamente frutas e hortaliças $(83,5 \%)$, principalmente banana e alface, respectivamente (Tabela 1). A maioria dos consumidores (81,5\%) consumia frutas e hortaliças orgânicas semanalmente (Figura 4) e considerava sua frequência de consumo satisfatória. Outros (16,5\%), porém, gostariam de elevar sua frequência de consumo; estes apontaram o preço elevado $(60,6 \%)$ e a baixa qualidade $(25,8 \%)$ como as principais razões para o seu descontentamento.

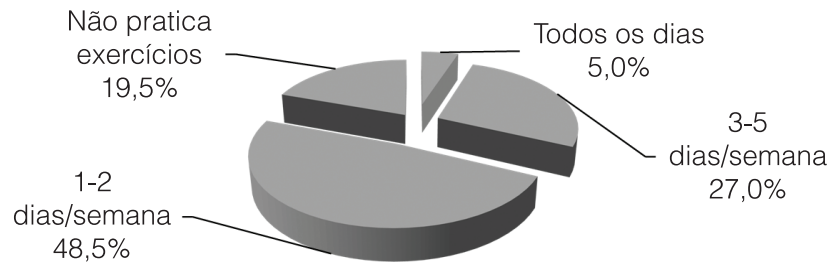

Figura 3. Frequência relativa com que os entrevistados praticavam exercícios físicos.

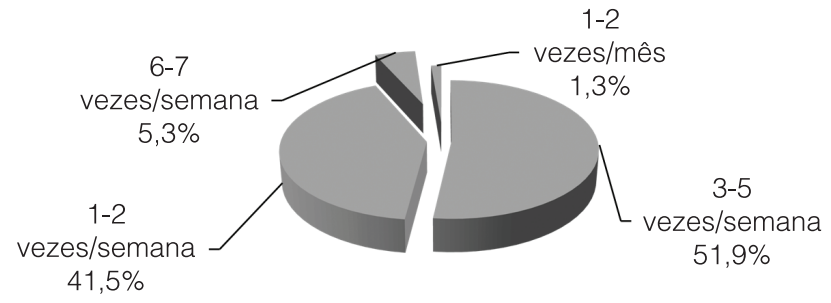

Figura 4. Frequência relativa de consumo de frutas e hortaliças orgânicas em Belo Horizonte - MG.
Apenas 16,5\% afirmaram consumir outros alimentos orgânicos além de frutas e hortaliças, incluindo produtos derivados de frutas $(67,8 \%)$, derivados de grãos e cereais $(21,5 \%)$, produtos apícolas $(9,2 \%)$ e derivados de hortaliças $(1,5 \%)$. Leite e derivados lácteos, bem como carnes, peixes e derivados, não foram citados. O elevado preço destes produtos $(64,7 \%)$ e a falta de interesse (18,6\%) foram as principais justificativas para o baixo consumo de outros produtos orgânicos (Tabela 2).

A preocupação com a saúde, o maior conteúdo de nutrientes e o sabor mais pronunciado foram as três maiores motivações para o consumo de frutas e hortaliças orgânicas (Figura 5). Estes resultados corroboram aqueles apresentados em estudos com consumidores de alimentos orgânicos brasileiros, os quais relataram motivações similares, como o bem-estar pessoal, a saúde, a longevidade e a qualidade de vida (PIMENTA, 2008; VILAS BOAS et al., 2006).

Após ser questionada sobre a influência da sustentabilidade do sistema de produção orgânica na decisão de compra de frutas e hortaliças orgânicas, parte considerável dos entrevistados (32,3\%) afirmou levar o fato em consideração no ato da compra (Figura 6). No

Tabela 1. Distribuição de frequência relativa de frutas e hortaliças orgânicas consumidas com maior frequência em Belo Horizonte.

\begin{tabular}{lclc} 
Frutas & $\begin{array}{r}\text { Frequência } \\
\text { relativa (\%) }\end{array}$ & Hortaliças & $\begin{array}{c}\text { Frequência } \\
\text { relativa (\%) }\end{array}$ \\
\hline Banana & 46,5 & Alface & 69,3 \\
Tomate & 12,5 & Couve & 15,3 \\
Morango & 12,3 & Brócolis & 7,0 \\
Laranja & 10,8 & Almeirão & 3,3 \\
Maçã & 7,5 & Salsa & 1,5 \\
Limão & 5,5 & Acelga & 1,5 \\
Uva & 2,3 & Cebolinha & 1,0 \\
\hline
\end{tabular}

Tabela 2. Distribuição de frequência relativa da principal justificativa para o baixo consumo de outros alimentos orgânicos além de frutas e hortaliças.

\begin{tabular}{lc}
\multicolumn{1}{c}{ Principal fator limitante } & $\begin{array}{c}\text { Frequência } \\
\text { relativa (\%) }\end{array}$ \\
\hline Preço muito elevado & 64,7 \\
Falta de interesse & 18,6 \\
Qualidade inferior em relação ao alimento & 10,5 \\
convencional & \\
Outro motivo & 4,2 \\
Baixa variedade dos alimentos & 1,2 \\
$\begin{array}{l}\text { Falta de confiabilidade de que o alimento seja } \\
\text { orgânico }\end{array}$ & 0,6 \\
$\begin{array}{l}\text { Distância elevada entre a residência e o local } \\
\text { de venda }\end{array}$ & 0,3 \\
\hline
\end{tabular}




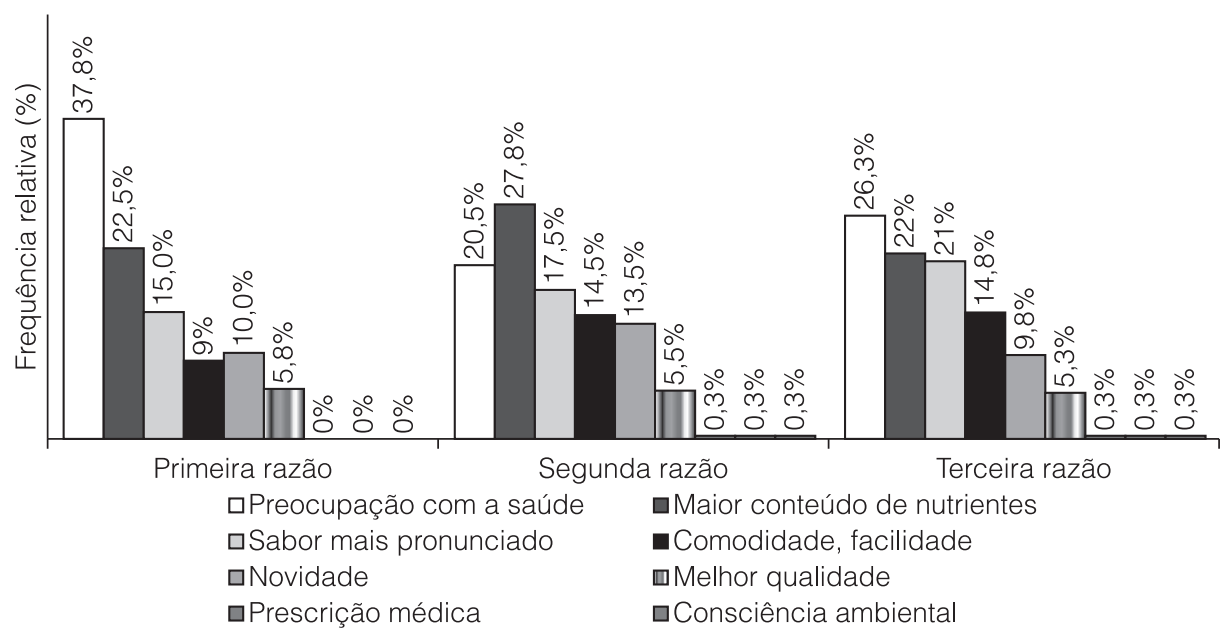

Figura 5. Distribuição de frequência relativa das três maiores razões para o consumo de frutas e hortaliças orgânicas.

$\square$ A sustentabilidade influencia na decisão de compra 口Não leva o fato em consideração

口Nunca refletiu sobre o assunto

-Outros fatores mais importantes são considerados

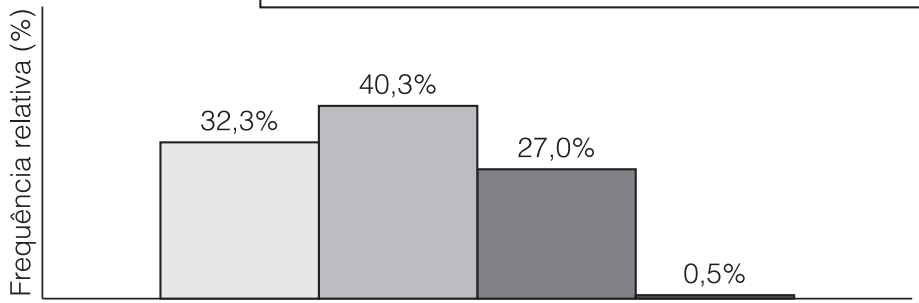

Figura 6. Distribuição de frequência relativa da influência da sustentabilidade do sistema de produção orgânica na decisão de compra de frutas e hortaliças orgânicas.

entanto, ainda que a consciência ambiental venha sendo considerada um fator que impulsiona o consumo destes alimentos (MAGNUSSON et al., 2003; PIMENTA, 2008; VILAS BOAS et al., 2006), a preocupação com o meio ambiente foi mencionada por apenas um consumidor, que a apontou entre as três principais justificativas para a compra (Figura 5). Portanto, os dados sugerem uma influência minoritária do tema sobre a decisão de compra de alimentos orgânicos, em que a preocupação em satisfazer interesses pessoais prevalece em detrimento do bem-estar da coletividade.

Por outro lado, o preço elevado, a baixa qualidade e a oferta irregular foram as principais dificuldades encontradas pelos consumidores para a compra destes alimentos (Figura 7). Vários estudos têm apontado o preço como uma das principais limitações para o consumo destes produtos (ANKOMAH e YIRIDOE, 2006; DIAZ et al., 2011).

O mercado consumidor de alimentos orgânicos em Belo Horizonte pode ser segregado em grupos distintos em se tratando do tempo de consumo (Figura 8), sendo que grande parte dos consumidores $(59,0 \%)$ tinha iniciado o consumo havia pelo menos cinco anos. Por outro lado, o consumo mais recente destes produtos, nos dois anos anteriores à pesquisa (26,5\%), evidencia o aumento da demanda em Belo Horizonte.

Em Belo Horizonte, frutas e hortaliças orgânicas eram adquiridas comumente no local de venda $(92,3 \%)$ ou diretamente com o produtor (7,8\%). Embora nenhum dos consumidores recebesse tais produtos em domicílio, a maioria gostaria de utilizar o serviço de entrega (92,3\%) sem, contudo, pagar taxas adicionais (72,8\%). Feiras ou locais específicos de comercialização de frutas e hortaliças orgânicas foram os locais de venda preferidos por $69,9 \%$ dos entrevistados, seguidos dos grandes supermercados $(14,8 \%)$ e mercados pequenos e de médio porte (15,3\%). A facilidade do acesso, o hábito e a maior variedade de alimentos orgânicos ofertados pelo estabelecimento foram as três maiores justificativas para a escolha do local de venda (Figura 9). A maioria considerou a disponibilidade de estabelecimentos em Belo Horizonte satisfatória $(86,8 \%)$ e a oferta destes 
Atitudes e motivações em relação ao consumo de alimentos orgânicos em Belo Horizonte - MG

ANDRADE, L. M. S. e BERTOLDI, M. C.

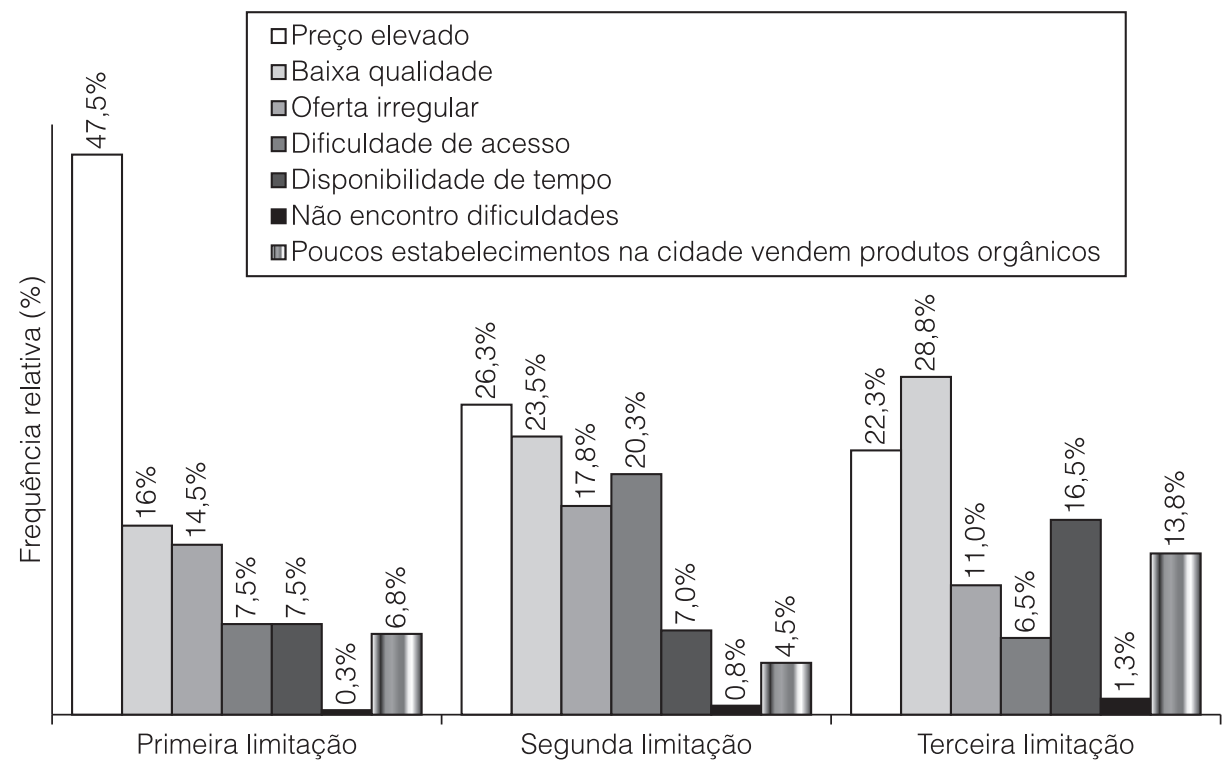

Figura 7. Distribuição de frequência relativa das três maiores limitações para o consumo de frutas e hortaliças orgânicas.

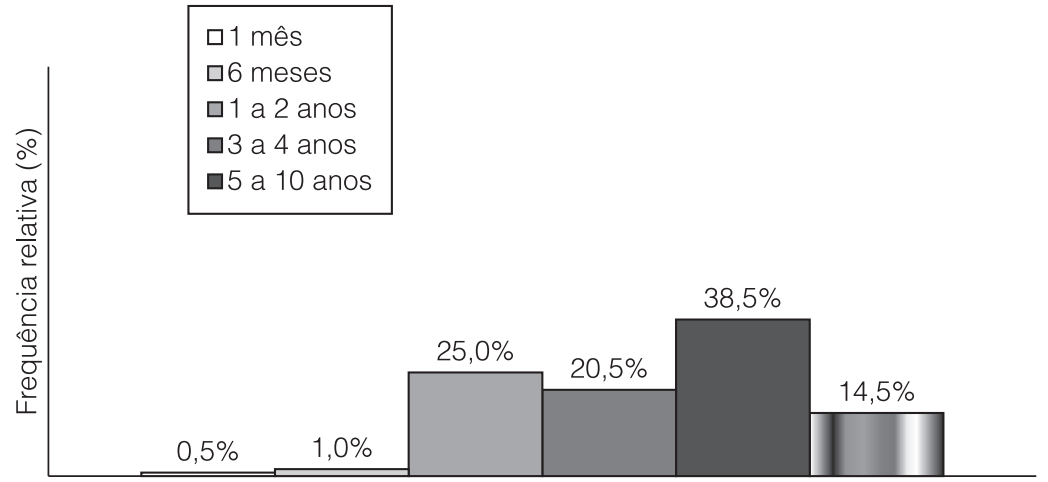

Figura 8. Distribuição de frequência relativa do tempo de consumo de alimentos orgânicos.

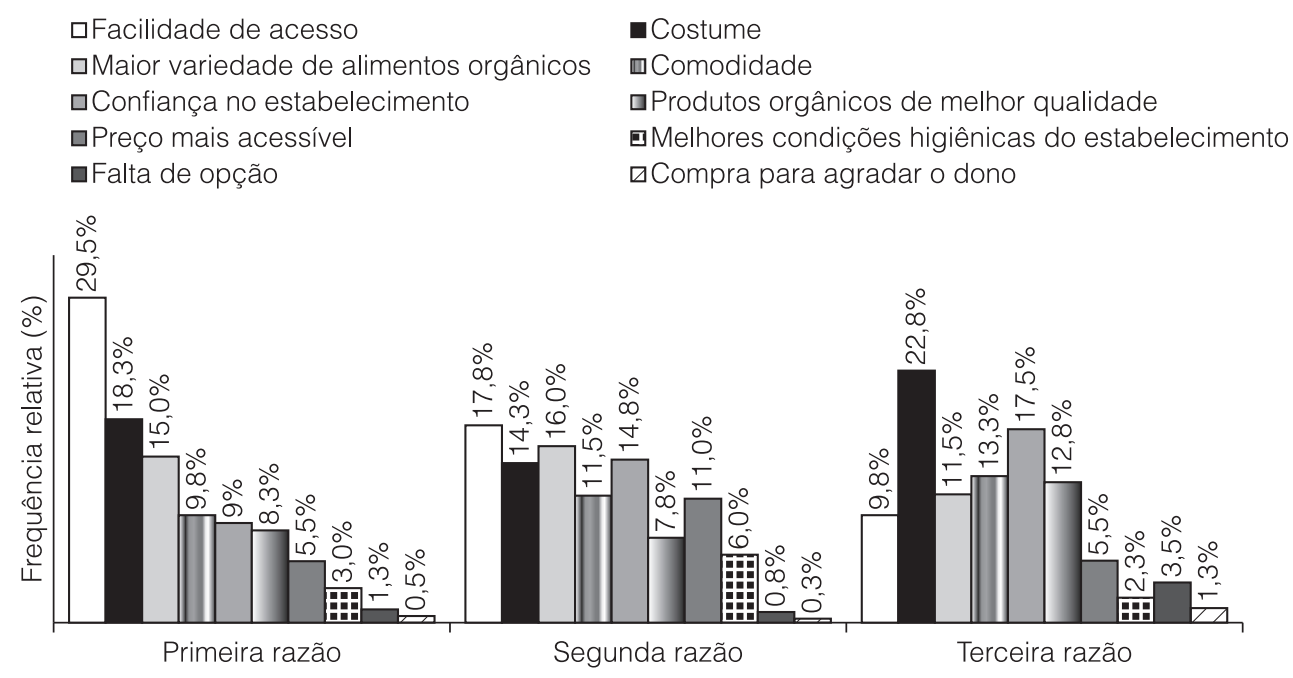

Figura 9. Distribuição de frequência relativa das três maiores razões para a escolha dos estabelecimentos. 
produtos, regular (84,3\%). Em relação à variedade de alimentos orgânicos encontrada no mercado, a maioria a considerou moderada $(79,3 \%)$, enquanto os demais opinaram como grande $(13,5 \%)$ e pequena $(7,3 \%)$.

Apenas 7,5\% dos entrevistados se certificavam se o produto era realmente orgânico pela presença do selo de certificação no produto, enquanto a maioria observava a identificação do local da compra $(59,3 \%)$ ou do produtor $(13,5 \%)$ (Figura 10). Além disso, cerca da metade $(50,5 \%)$ dos consumidores não soube dizer se o selo de certificação estava presente nos alimentos orgânicos que eles consumiam por não conhecer o selo (Figura 11), o que demonstra a necessidade de maiores informações sobre o assunto ao consumidor. Este comportamento pode ser explicado, uma vez que a obrigatoriedade do uso do

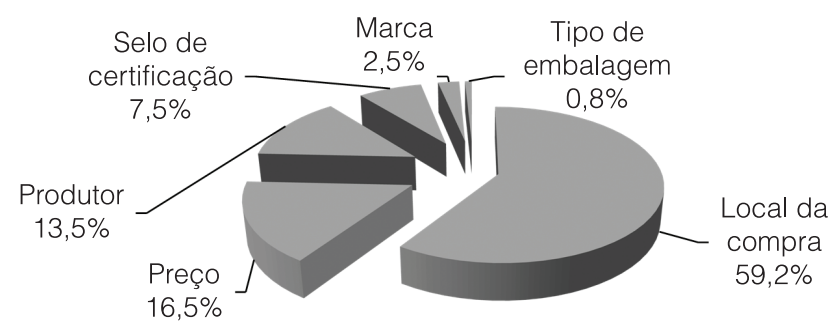

Figura 10. Distribuição de frequência relativa das formas utilizadas pelos consumidores para identificar alimentos orgânicos. selo único oficial do Sistema Brasileiro de Avaliação da Conformidade Orgânica (SISORG) no rótulo de alimentos orgânicos entrou em vigor recentemente (janeiro de 2011), seis a doze meses antes da coleta de dados (BRASIL, 2009). Além disso, outra forma de identificação dos alimentos orgânicos, geralmente desconhecida pelos consumidores, é a declaração de cadastro do agricultor familiar nas Superintendências Federais de Agricultura (SFAs), que o isenta da obrigatoriedade do uso do selo único no produto; porém, esta exceção está condicionada à venda direta do produto ao consumidor, bem como à exposição do cadastro no local de venda. Percebe-se que, na prática, o consumidor tende a reconhecer o local onde estes alimentos são comumente comercializados como, por exemplo, as feiras tradicionais de alimentos orgânicos em Belo Horizonte.

Apenas a minoria $(32,5 \%)$ afirmou ter o hábito de ler o rótulo dos produtos. Segundo os entrevistados, a presença de informações específicas no rótulo era essencial para a efetivação da compra do produto, dentre as quais informações sobre benefícios à saúde $(26,9 \%)$ e presença do selo de certificação $(17,7 \%$ ) (Tabela 3).

Uma parcela significativa (42,5\%) dos consumidores preferiria adquirir frutas e hortaliças orgânicas, mesmo que sua qualidade fosse inferior à dos alimentos convencionais, em termos de cor, aparência e textura. Entretanto, a maioria (55,3\%) não estava disposta a pagar nada a mais para adquiri-los (Figura 12). Segundo

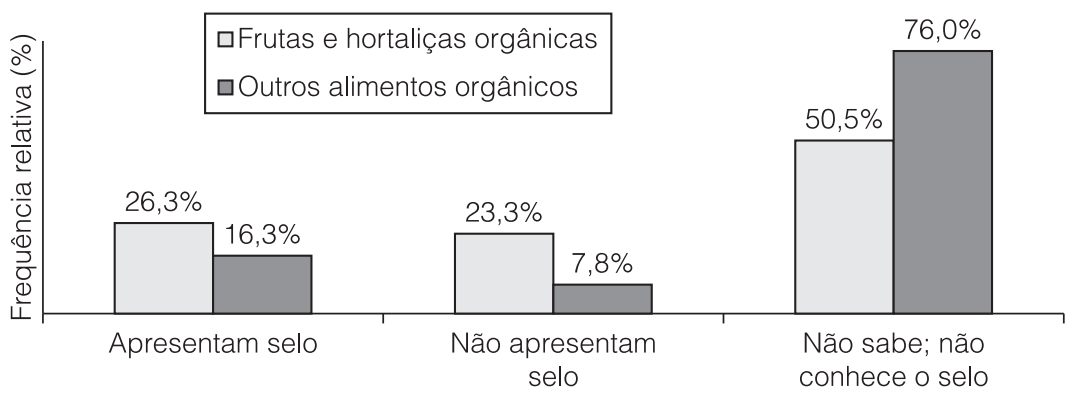

Figura 11. Distribuição de frequência relativa do conhecimento dos consumidores sobre a presença de selo de certificação em frutas e hortaliças orgânicas, e outros alimentos orgânicos.

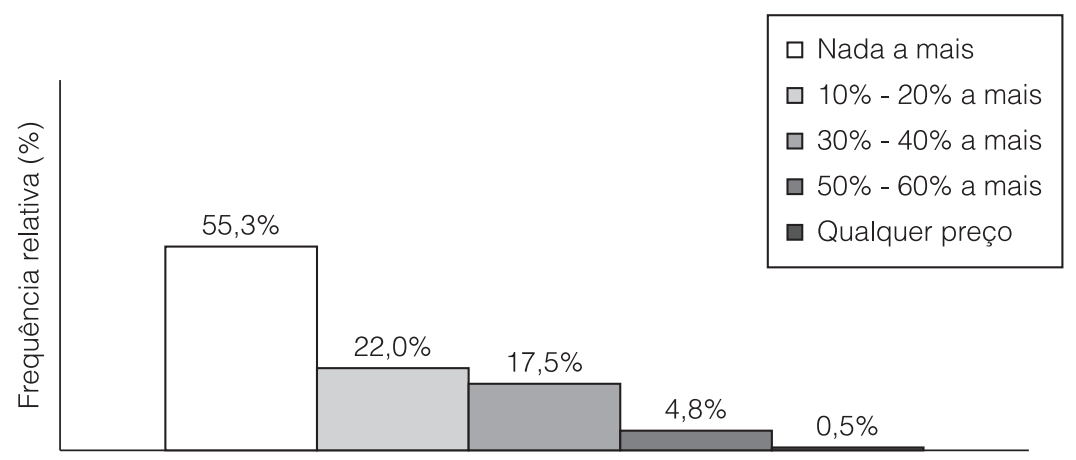

Figura 12. Distribuição de frequência relativa da razão entre o preço máximo pago pelo consumidor por um alimento orgânico em relação àquele pago por um alimento convencional, comercializado nas mesmas condições. 
Tabela 3. Distribuição de frequência relativa da informação mais importante presente no rótulo, que determinaria a efetivação da compra do alimento orgânico pelo consumidor.

\begin{tabular}{lc}
\multicolumn{1}{c}{$\begin{array}{c}\text { Informação essencial para } \\
\text { a decisão de compra }\end{array}$} & $\begin{array}{c}\text { Frequência } \\
\text { relativa (\%) }\end{array}$ \\
\hline $\begin{array}{l}\text { Informações sobre benefícios à saúde } \\
\text { Selo de certificação }\end{array}$ & 26,9 \\
Presença de nutrientes adicionais ou em maior & 17,7 \\
quantidade & 15,4 \\
Marca & 14,6 \\
Valor calórico & 13,1 \\
Origem do produto & 7,7 \\
Selo de qualidade & 3,1 \\
Ausência ou redução de constituintes & 1,5 \\
específicos & \\
\hline
\end{tabular}

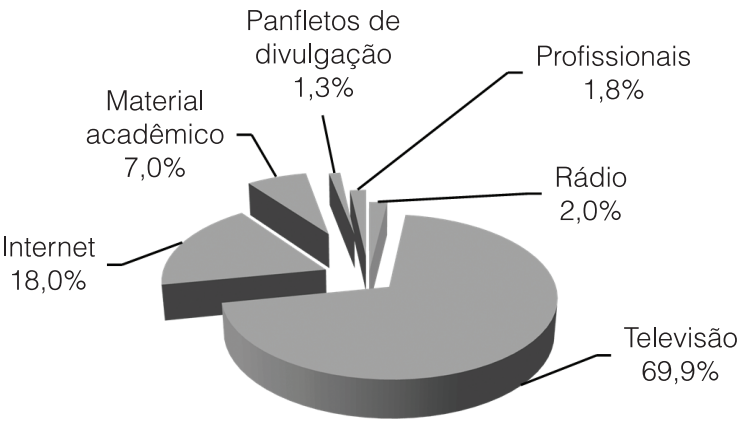

Figura 13. Distribuição de frequência relativa do meio de comunicação mais utilizado pelo consumidor para obter informações sobre alimentos orgânicos.

Ankomah e Yiridoe (2006), o preço é realmente um fator crítico que limita o crescimento do setor de orgânicos, o que também pode ser observado neste estudo (Tabela 2 , Figura 11).

A televisão (70,0\%) foi o meio de comunicação mais citado pelos entrevistados para obter informações sobre alimentos orgânicos, seguida da internet (18,0\%); a consulta a profissionais da área foi mencionada apenas por uma pequena parcela dos entrevistados $(1,8 \%)$ (Figura 13). Grande parte dos consumidores acreditava que tanto o acesso a essas informações (53\%) quanto o volume de informações $(60,5 \%)$ eram suficientes. Além disso, a maioria declarou confiança de plena $(26,0 \%)$ a razoável $(59,8 \%)$ nos meios de comunicação utilizados.

\section{Conclusão}

Em Belo Horizonte - MG, frutas e hortaliças foram os alimentos orgânicos mais consumidos em 2011. Mulheres com escolaridade e poder aquisitivo elevados, em união estável e com filhos, constituíram os maiores consumidores destes produtos. Apesar de ser geralmente motivada pelos benefícios à saúde advindos do consumo destes produtos, grande parte dos consumidores apresentou conhecimento superficial sobre a temática, o que evidenciou a necessidade de maiores esclarecimentos sobre o assunto, especialmente em se tratando da forma de identificação do produto orgânico. Uma demanda reprimida por tais produtos pôde ser observada, pois, apesar do grande interesse por alimentos orgânicos, fatores como preço elevado e baixa qualidade limitaram o consumo destes alimentos na região.

\section{Agradecimentos}

À Pró-Reitoria de Pesquisa e Pós-graduação da Universidade Federal de Ouro Preto, pela concessão de Bolsa de Iniciação Científica. Aos estabelecimentos e feiras comerciais, onde foi realizada a pesquisa.

\section{Referências}

ANKOMAH, B. S.; YIRIDOE, E. K. Organic and Conventional Food: A Literature Review of the Economics of Consumer Perceptions and Preferences. Nova Scotia: Organic Agriculture Center of Canada in Nova Scotia Agricultural College, 2006. Final report.

BRASIL. Ministério da Agricultura e do Abastecimento. Lei $n^{\circ}$ 10.831, de 23 de dezembro de 2003. Dispõe sobre a agricultura orgânica e dá outras providências. Diário Oficial da República Federativa do Brasil, Brasília, DF, 24 dez. 2003. Seção 1, n. 250, p. 8.

BRASIL. Ministério da Agricultura e do Abastecimento. Instrução Normatica Interministerial n²8, de 08 de junho de 2011. Estabelece Normas Técnicas para os Sistemas Orgânicos de Produção Aquícola a serem seguidos por toda pessoa física ou jurídica responsável por unidades de produção em conversão ou por sistemas orgânicos de produção. Diário Oficial da República Federativa do Brasil, Brasília, DF, 09 jun. 2011. Seção 1.

BRASIL. Ministério da Agricultura e do Abastecimento. Instrução Normatica $n^{\circ} 50$, de 05 de novembro de 2009. Institui o selo único oficial do Sistema Brasileiro de Avaliação da Conformidade Orgânica e estabelece os requisitos para a sua utilização nos produtos orgânicos. Diário Oficial da República Federativa do Brasil, Brasília, DF, 06 nov. 2009. Seção 1.

DIAZ, F. J. M.; PLEITE, F. M. C.; MARTINEZ-PAZ, J. M.; GARCIA, P. G. Willingness to pay for organic food in Spain: an approach to the analysis of regional differences. Itea-Informacion Tecnica Economica Agraria, Zaragoza, v. 107, n. 1, p. 3-20, 2011.

ENDO, E.; BERTOLDI, M. C.; PINHEIRO, N. M. S.; ARRUDA, A. C.; MINIM, V. P. R. Caracterização do mercado consumidor de água aromatizada da cidade de Juiz de Fora/MG. Ciência e 
Atitudes e motivações em relação ao consumo de alimentos orgânicos em Belo Horizonte - MG

ANDRADE, L. M. S. e BERTOLDI, M. C.

Tecnologia de Alimentos, Campinas, v. 29, n. 2, p. 1-6, 2009. http://dx.doi.org/10.1590/S0101-20612009000200020

FOOD AND AGRICULTURE ORGANIZATION OF THE UNITED NATIONS - FAO. Disponível em: <htpp://www.fao.gov>. Acesso em: 10 jan. 2011.

GUIVANT, J. S. Os supermercados na oferta de alimentos orgânicos: apelando ao estilo de vida ego-trip. Ambiente e Sociedade, Campinas, v. 6, n. 2, p. 63-81, 2003.

HOEFKENS, C.; VERBEKE, W.; AERTSENS, MONDELAERS K.; VAN CAMP J. The nutritional and toxicological value of organic vegetables: Consumer perception versus scientific evidence. British Food Journal, Bingley, v. 111, n. 10, p. 1062-1077, 2009. http://dx.doi.org/10.1108/00070700910992916

INSTITUTO BRASILEIRO DE GEOGRAFIA E ESTATÍSTICA - IBGE. Disponível em: <htpp://www.ibge.com.br>. Acesso em: 05 jan. 2011

ILYASOGLU, H.; TEMEL, S.; OZCELIK, B. Consumer perceptions of organic foods in Turkey. Journal of Food Agriculture \& Environment, Helsinki, v. 8, n. 3-4, p. 279-281, 2010.

MAGNUSSON, M. K.; ARVOLA, A.; HURSTI UKK, A. L.; SJODEN, P. O. Choice of organic foods is related to perceived consequences for human health and to environmentally friendly behaviour. Appetite, London, v. 40, n. 2, p. 109-117, 2003. http:// dx.doi.org/10.1016/S0195-6663(03)00002-3

MEI-FANG, C. Consumer attitudes and purchase intentions in relation to organic foods in Taiwan: moderating effects of foodrelated personality traits. Food Quality and Preference, Barking, v. 18, n. 7, p. 1008-1021, 2007. http://dx.doi.org/10.1016/j. foodqual.2007.04.004
NESS, M. R.; NESS, M.; BRENNAN, M.; OUGHTON, E.; RITSON, C.; RUTO, E. Modelling consumer behavioural intentions towards food with implications for marketing quality low-input and organic food. Food Quality and Preference, Barking, v. 21, n. 1, p. 100-111, 2010. http://dx.doi.org/10.1016/j. foodqual.2009.08.012

PIMENTA, M. L. Comportamento do Consumidor de Alimentos Orgânicos na Cidade de Uberlândia: um Estudo com Base na Cadeia de Meios e Fins. 2008. 125 f. Dissertação (Mestrado em Administração)-Universidade Federal de Uberlândia, Uberlândia, 2008.

ROITNER-SCHOBESBERGER, B.; DARNHOFER, I.; SOMSOOK, S.; VOGL, C. R. Consumer perceptions of organic foods in Bangkok, Thailand. Food Policy, Guildford, v. 33, n. 2, p. 112-121, 2008. http://dx.doi.org/10.1016/j.foodpol.2007.09.004

SCIALABBA, N. E. Global Trends in Organic Agriculture Markets and Countries' Demand for FAO Assistance. Roma: FAO, 2005.

SILVA, D. M. Produtos Orgânicos: Uma Análise do Varejo e do Consumidor nos Supermercados de Londrina, PR. 2003. 149 f. Dissertação (Mestrado em Administração)Universidade Estadual de Londrina, Londrina, 2003.

VILAS BOAS, S. H. T.; SETTE, R. S.; BRITO, M. J. Comportamento do consumidor de produtos orgânicos: uma aplicação da cadeia de meios e fins. Organizações Rurais \& Agroindustriais, Lavras, v. 8, n. 1, p. 25-39, 2006.

WILLIAMS, P. R. D.; HAMMITT, J. K. Perceived risks of conventional and organic produce: Pesticides, pathogens, and natural toxins. Risk Analysis, New York, v. 21, n. 2, p. 319-330, 2001. PMid:11414540. http://dx.doi.org/10.1111/0272-4332.212114 